\title{
Performance Comparison between PSO and GA in Improving Dynamic Voltage Stability in ANFIS Controllers for STATCOM
}

\author{
Huu Vinh Nguyen \\ Ho Chi Minh City Power Corporation \\ Ho Chi Minh City, Vietnam \\ nguyenhuuvinhdlhcm@gmail.com
}

Minh Tien Cao

Faculty of Telecommunications Engineering

Telecommunications University

Nha Trang City, Vietnam

caominhtienkvtd@gmail.com

\author{
Hung Nguyen \\ HUTECH Institute of Engineering \\ Ho Chi Minh City University of Technology (HUTECH) \\ Ho Chi Minh City, Vietnam \\ n.hung@hutech.edu.vn \\ Kim Hung Le \\ Faculty of Electrical Engineering \\ The University of Danang-University of Science and \\ Technology, Vietnam \\ lekimhung@dut.udn.vn
}

\begin{abstract}
One of STATCOM's advantages is its quick response to disturbances in the power systems. The controller of STATCOM is commonly a PID controller. However, the PID controller is usually only highly effective at one or some operation points. In order to improve operational efficiency of the controller of STATCOM, the proposed ANFIS-PSO and ANFIS-GA controllers have been studied and applied to the studied power system. To demonstrate the performance of the proposed controllers, simulations of the voltage response in timedomain were performed in MATLAB to evaluate the effectiveness of the designed controllers for STATCOM. The simulation results showed that the proposed controllers can be used to improve the system stability as well as the voltage quality more effectively than the conventional PID controller. The ANFIS PSO controller carried out the best response after the occurrence of a three-phase short circuit fault.
\end{abstract}

Keywords-STATCOM; adaptive neuro-fuzzy inference system (ANFIS); particle swarm optimization (PSO); genetic algorithm (GA); proportional integral derivative (PID); voltage stability

\section{INTRODUCTION}

Voltage stability issues are always concerned by the power system operator. In enhancing voltage stability using reactive power compensator [1], the series capacitors can minimize reactive power loss, enhance voltage and gain the power transfer ability of the transmission line. The use of capacitors for compensating is very beneficial but it cannot improve transient stability after fault conditions or other complicated operation conditions as short-circuit in two-phase or threephase. For solving this case, flexible AC transmission system (FACTS) devices were proposed to be implemented to the power grid for improving the stability of the power system. Static synchronous compensator (STATCOM) is one of the most suitable devices that can be used not only to maintain the Corresponding author: Huu Vinh Nguyen voltage at the connected bus but also to improve the dynamic stability of the system [2-7]. STATCOM is applied to improve the operational and control performance of the power system such as power transfer capability, voltage regulation, reactive power management, stability limits, power factor improvement, etc [2]. In [3], a new control strategy using a full-power wind permanent-magnet generator (PMG) with a STATCOM is proposed to compensate reactive power for improving transient voltage stability during and after faults. Authors in [4] examined the use of STATCOM in improving voltage stability and performance of a DFIG-based wind farm interconnected to a weak distribution system due to the effects of transient disturbances such as three phase fault, step load change, voltage swelling and sagging in the system. In [5], the results showed that STATCOM can significantly improve the high voltage ride through capability of type-D wind turbine and prevents it from being disconnected from the grid during voltage swell in the grid side. Authors in [6] presented a design procedure for STATCOM which constantly updates the parameters of the PI controller to enhance the voltage profile of the multi-machine system under dynamic disturbances. Besides that, STATCOM can be combined with Power System Stabilizer (PSS) in multi-machine power systems for improving the voltage profile and damping oscillations of synchronous generators under normal and abnormal network conditions [7].

Commonly, PID controllers are used to control STATCOMs. The PID controllers have robust performance across a wide range of operating conditions and functional simplicity. However, the high nonlinearity of the power system means that a PID controller can provide robust performance at a particular operating range. Recently, many controllers have been applied to improve the efficiency of the device, such as the hybrid Proportional Integral plus Fuzzy Logic (PI+FL) 
damping controller designed for STATCOM to improve the voltage stability of a multi-machine system when a three phase short circuit occurs [8]. In addition, a fuzzy logic controller is designed for STATCOM to enhance the transient stability of an interconnected power system during fault occurrence. The results indicate that the fuzzy logic based STATCOM controller gives improved performance compared with the PI based STATCOM controller [9]. However, the main disadvantage of fuzzy logic controllers is that they depend on the programmer's experience. Combining algorithms to exploit the advantages of each is a good solution that is being widely researched. In [10], the author proposed an algorithm that combined fuzzy logic and artificial neural networks called Adaptive-Network-based Fuzzy Inference System (ANFIS). ANFIS is a good structure for designing a controller of SVC to damp power system oscillations and enhance system stability [11]. The effectiveness of the proposed controller is demonstrated on an SVC located at the middle of a transmission line connecting a generator to an infinite bus. The ANFIS control algorithm gained attention due to its robustness in nonlinear systems. An intelligent controller that combined ANFIS and Fuzzy turning of PID was designed to control a STATCOM to enhance power quality in a power system in [12].

This paper presents the ANFIS-PSO and ANFIS-GA controllers of STATCOM for transient stability improvement of the power system after large disturbances. The controllers combine the optimal searching method of PSO and GA in ANFIS controller for optimal system operation. Simulation results illustrate the effectiveness of the proposed controllers in enhancing system stability.

\section{SYSTEM CONFIGURATION}

\section{A. Studied System Configuration}

The studied system in this paper is the power network installed in Ho Chi Minh City, Vietnam, shown in Figure 1

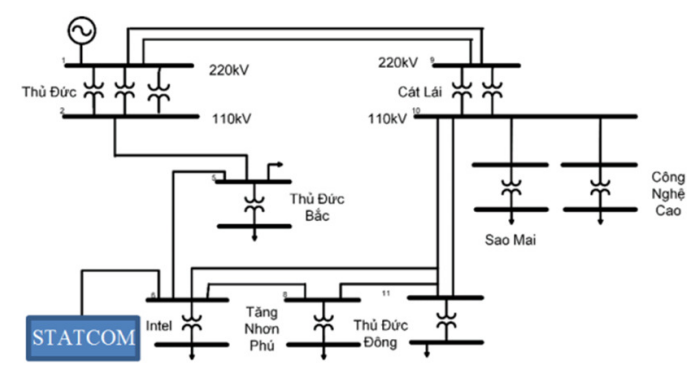

Fig. 1. Single line diagram of the Thu Duc power network.

During the last year some faults occurred in the Thu Duc power network, which is relevant to the Intel bus. Intel is a semiconductor producing company and it is very sensitive to power faults. The requirements for the power network stability are extremely strict in the current circumstance. For these reasons, it was decided to study the issue of Thu Duc power network using Matlab. As shown in Figure 1, a STATCOM is installed at the Intel bus for investigating its efficiency in gaining voltage value. The Thu Duc power transmission system has a $220 \mathrm{kV}$ power source instead of the transmission line transferring the power from other $220 \mathrm{kV}$ bus and five 250MVA step-down transformers for reducing the voltage from $220 \mathrm{kV}$ to $110 \mathrm{kV}$, which is a loop circuit from Thu Duc bus to Cat Lai bus. Besides, a 15MVA STATCOM is also installed at the Intel bus for researching its effectiveness and the voltage stability of the studied system. There are six load buses, namely Thu Duc Bac, Intel, Tang Nhon Phu, Thu Duc Dong, Sao Mai, Cong Nghe Cao.

\section{B. STATCOM Modeling}

A STATCOM is designed for regulating the voltage at its terminals by compensating the amount of reactive power in or out of the power system. When the system voltage is low, the STATCOM injects the reactive power to the power system. When the voltage is high, it absorbs the reactive power. Besides, a STATCOM can be designed to act as an active filter to absorb system harmonics [13]. For analyzing the STATCOM, a mathematical model is used, in which the output voltage is separated into two components represented in $d$ and $q$ axes as follows [14-15]:

$$
\begin{aligned}
& v_{d s t a}=V_{d c s t a} \cdot k m_{s t a} \cdot \sin \left(\theta_{b u s}+\alpha_{s t a}\right) \\
& \mathrm{v}_{\mathrm{qsta}}=V_{d c s t a} \cdot k m_{s t a} \cdot \cos \left(\theta_{b u s}+\alpha_{s t a}\right)
\end{aligned}
$$

where $v_{d s t a}$ and $v_{q s t a}$ are the voltages of $d$ and $q$ axes at the output terminals of the STATCOM, $\mathrm{km}_{\text {sta }}$ is the modulation index of the STATCOM, $\alpha_{\text {sta }}$ is the phase angle of the STATCOM, $\theta_{\text {bus }}$ is the voltage phase angle of the common AC bus, and $V_{d c s t a}$ is the DC voltage of the DC capacitor $C_{m}$. The relationship between DC voltage and current of the DC capacitor can be described as:

$$
\left(C_{m}\right) p\left(V_{d c s t a}\right)=\omega_{b}\left[I_{d c s t a}-\left(V_{d c s t a} / R_{m}\right)\right]
$$

where $I_{d c s t a}$ is the pu DC current flowing into the positive terminal of $V_{d c s t a}, R_{m}$ is the pu equivalent resistance considering the equivalent electrical losses of the STATCOM, and $i_{q s t a}$ and $i_{d s t a}$ are the currents in $q$ and $d$ axes flowing into the terminals of the STATCOM respectively. The fundamental control block diagram of the STATCOM including damping controller is shown in Figure 2. The DC voltage $V_{d c s t a}$ is controlled by the phase angle $\alpha_{\text {sta }}$ while the voltage $v_{\text {sta }}$ is varied by changing the modulation index $\mathrm{km}_{\text {sta }}$.

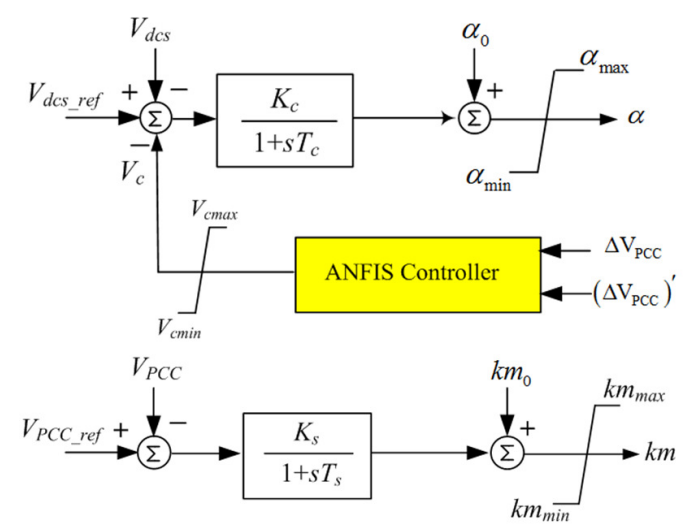

Fig. 2. Control scheme of STATCOM 


\section{ADAPTIVE NEURO-FUZZY INFERENCE SYSTEM}

ANFIS discriminates itself from normal fuzzy logic systems by its adaptive parameters, i.e. both premise and consequent parameters are adjustable. A typical architecture of the used ANFIS is shown in Figure 3, in which a circle indicates a fixed node, whereas a square indicates an adaptive node. For simplicity, we consider two inputs $x, y$ and one output $f$. Among the many FIS models, the Sugeno fuzzy model is the most widely applied one for its high interpretability and computational efficiency, and built-in optimal and adaptive techniques. For each model, a common rule set with two fuzzy if-then rules can be expressed as [16]:

Rule $i$ : if $x$ is $A i$ and $y$ is $B i$ then $f i=p_{i} x+q_{i} y+r_{i}$.

where $A_{i}$ and $B_{i}$ are fuzzy sets in the antecedent and $z=f(x, y)$ is a crisp function in the consequent. $p_{i}, q_{i}, r_{i}$ are the updating parameters of the rule.

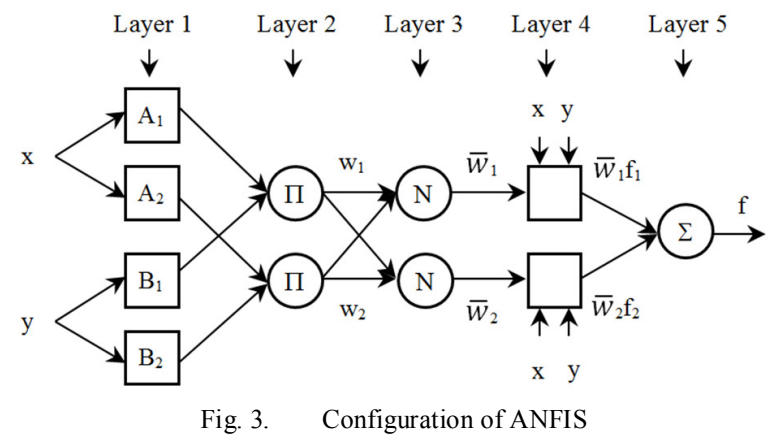

Each ANFIS consists of five layers [16]:

- Layer 1: In this layer, input fuzzification takes place. Mathematically, this function can be expressed as:

$$
O_{i j}^{(1)}=\mu_{j}\left(I_{i j}^{(1)}\right)
$$

where $O_{i j}^{(1)}$ is the Layer 1 node's output which corresponds to the $j$-th linguistic term of the $i$-th input variable $I_{i j}^{(1)}, i$ is the number of input variable and $j$ is the number of linguistic terms of each input. In this research, $i=2$ and $j=5$.

$$
\mu_{j}\left(I_{i j}^{(1)}\right)=\frac{1}{1+\left|\frac{x_{i}-c_{i j}}{a_{i j}}\right|^{b_{i j}}}
$$

where the triplet of parameters $\left(a_{i j}, b_{i j}, c_{i j}\right)$ are referred to as premise parameters or non-linear parameters and they adjust the shape and the location of the membership function. Those parameters are adjusted during the training mode of operation by the error back-propagation algorithm.

- Layer 2: The total number of rules in this layer is 25. Each node output represents the activation level of a rule, with $k$ representing rule number:

$$
O_{k}^{(2)}=w_{k} \prod_{i=1}^{q} O_{i j}^{(1)}
$$

- Layer 3: The output of the $k$-th node is the firing strength of each rule divided by the total sum of the activation values of all the fuzzy rules. This results in the normalization of the activation value for each fuzzy rule. This operation is simply written as:

$$
O_{k}^{(3)}=\bar{w}_{k}=\frac{O_{k}^{(2)}}{\sum_{m=1}^{y} O_{m}^{(2)}}
$$

- Layer 4: Each node $k$ in this layer is accompanied by a set of adjustable parameters $d_{1 k}, d_{2 k}, \ldots, d_{N_{\text {input }}}, d_{y k}, d_{0}$, and implements the linear function:

$$
\begin{aligned}
& O_{k}^{(4)}=\bar{w}_{k} f_{k} \\
& O_{k}^{(4)}=\left(d_{1 k} I_{1}^{(1)}+d_{2 k} I_{2}^{(1)}+\ldots+d_{\text {Ninputk }} I_{1}^{(1)}+d_{0 k}\right)
\end{aligned}
$$

- Layer 5: The single node in this layer computes the overall output as the summation of all incoming signals, which is expressed as:

$$
O_{k}^{(5)}=\sum_{k=1}^{y} O_{k}^{(4)}=\sum_{k=1}^{y} \bar{w}_{k} f_{k}=\frac{\sum_{k=1}^{y} w_{k} f_{k}}{\sum_{k=1}^{y} w_{k}}
$$

\section{A. Particle Swarm Optimization (PSO) Algorithm}

PSO is a meta-heuristic algorithm, inspired by the collective intelligence and behavior of birds and fish. This algorithm was at first based on simple mathematical relations, considering the movement patterns of birds for the optimization of complex problems [17]. The algorithm starts by randomly creating an initial population. In fact, each particle shows a possible response. Each particle starts to move and search in the problem space in order to find the most appropriate point. In each step, this particle is fitted by its objective function and is placed toward the most appropriate direction to determine the most accurate and precise response. Each particle continues its movement each time using its experience and its neighbors in the problem search space. Other particles move towards the particle with the best position and correct their directions. Therefore, the movement of particles in the problem search space depends on three factors including the present position of the particle, the best location that a particle has experienced, and the best location of all the particles. In each cycle, the aim is to identify a particle that finds the best momentary position and the other particles move towards it considering the superiority of the most appropriate particle in terms of location. This continues until all particles gather together at the best point [18]. These calculations are based on (10) and (11):

$$
\begin{gathered}
V_{i}^{(k+1)}=w V_{i}^{(k)}+c_{1} r_{1}\left(\text { pbest }_{i}-X_{i}^{(k)}\right) \\
+c_{2} r_{2}\left(\text { gbest }_{i}-X_{i}^{(k)}\right) \\
V_{i}^{(k+1)}=X_{i}^{(k)}+V_{i}^{(k)}
\end{gathered}
$$

In (10), $i=1, \ldots, N$, where $N$ is the population size, and $k=1,2,3, \ldots$ is the iteration number in the algorithm process. 
$V_{i}^{(k+1)}$ is the new velocity vector for the $i^{\text {th }}$ particle, $V_{i}^{(k)}$ indicates the existing velocity vector for the $i^{\text {th }}$ particle, pbest $t_{i}$ is the best position that the $i^{\text {th }}$ particle has experienced, and gbest is the best experienced position of all particles. In (11), $X_{i}^{(k)}$ is the present position of the $i^{\text {th }}$ particle and the new position of the $i^{\text {th }}$ particle, $w$ is the weight inertia, which is used in the class of particles to ensure the convergence and is suggested to be in the range of 0.4-0.9, $r_{1}$ and $r_{2}$ are random numbers from 0 up to $1, c_{1}$ and $c_{2}$ are two fixed and positive values that are introduced as the personal learning factor and the global learning factor respectively, and have a significant role in the algorithm's convergence controlling process. It is worth mentioning that the condition $c_{1}+c_{2} \leq 4$ must always be met. The steps of PSO are: (1) Initialize the swarm of particles in random positions within the hyperspace. (2) Evaluate the performance of each particle, using its current position. (3) Compare the performance of each individual to its best performance. (4) Change the velocity vector for each particle. (5) Move each particle to a new position. (6) Go to 2 and repeat until convergence. The parameters are initialized randomly in step (1), then they are being updated in each cycle. In the first iteration $\{a i\}$ are updated, then in the second iteration $\{b i\}$ are updated, then $\{c i\}$ are updated and then after updating all parameters again $\{a i\}$ are updated and the process is repeated.

\section{B. Genetic Algorithm (GA)}

$\mathrm{GA}$ is a random search technique that imitates natural evolution with Darwinian survival of the fittest approach. It can handle any kind of objective function and constraints without many mathematical requirements. The population strategy enables GA to search near optimal solutions from various parts and directions simultaneously within a search space [19]. GA uses random choice and probabilistic decision to guide the research, where the population improves towards near-optimal point from generaton to generation. In GA, the problem's variables are represented as genes in a chromosome, and the chromosomes are evaluated according to their fitness values. The chromonosomes with better fitness are found through the three basic operations of GA: selection, crossover and mutation. The genetic operators alter the composition of genes in order to create new chromosomes, called offspring, and with the selection operator, chromosomes with better fitness have higher probabilities of being selected in the next generation.

Genetic algorithm's steps are:

1. Generate the initial population.

2. Generate the consequent parameters for every chromosome.

3. Evaluation of each chromosome in the population using the objective function, and storing the best chromosomes.

4. Employing the genetic operator to obtain new chromosomes (selection, crossover, and mutation).

5. Generate the parameters for each of the new elements.

6. Evaluation of each chromosome, and storing of the new best chromosomes.

7. If the stopping criterion is validated then the paramerters are stored, else return to step 4.
8. Recover of the best particle.

\section{SimULATION RESUlTS}

The task of a learning algorithm is to tune all the modifiable parameters to make the ANFIS output match the training data. The overall output is a linear combination of the modifiable parameters. The training algorithms require a training set between inputs and outputs. In this paper, both training algorithms PSO and GA were used to optimize membership function parameters of ANFIS in order to minimize the cost function which is RMSE.

$$
R M S E=\sqrt{\frac{1}{n} \sum_{i=1}^{n}\left(x_{i}-y_{i}\right)^{2}}
$$

The data sets that are required for training purposes are obtained using a PID controller with a sample time of $0.001 \mathrm{~s}$. Characteristics of the initial parameters of ANFIS, PSO and GA are shown in Tables I, II, and III respectively.

TABLE I. CHARACTERISTICS OF THE ANFIS MODEL

\begin{tabular}{|l|c|}
\hline \multicolumn{1}{|c|}{ ANFIS parameter } & Value \\
\hline Type & Sugeno \\
\hline Number of clusters & 5 \\
\hline Inputs/outputs & {$\left[\begin{array}{ll}2 & 1\end{array}\right]$} \\
\hline Number of input MFs & {$\left[\begin{array}{ll}5 & 5\end{array}\right]$} \\
\hline Number of training data & 1250 \\
\hline
\end{tabular}

TABLE II. PSO PARAMETERS

\begin{tabular}{|l|c|}
\hline \multicolumn{1}{|c|}{ PSO parameter } & Value \\
\hline Population size & 25 \\
\hline Maximum number of iterations & 1000 \\
\hline Inertia weight $(w)$ & 1 \\
\hline Personal learning coefficient $\left(c_{1}\right)$ & 1 \\
\hline Global learning coefficient $\left(c_{2}\right)$ & 2 \\
\hline Inertia weight damping ratio $\left(w_{\text {damp }}\right)$ & 0.99 \\
\hline
\end{tabular}

TABLE III. GA PARAMETERS

\begin{tabular}{|l|c|}
\hline \multicolumn{1}{|c|}{ GA parameter } & Value \\
\hline Population size & 25 \\
\hline Maximum number of iterations & 1000 \\
\hline Crossover percentage $\left(p_{c}\right)$ & 0.4 \\
\hline Mutation percentage & 0.7 \\
\hline Mutation rate $(\mu)$ & 0.15 \\
\hline Selection pressure $(\beta)$ & 8 \\
\hline
\end{tabular}

The proposed models have acceptable accuracy and $R M S E_{P S O}=0.20036$ and $R M S E_{G A}=0.20037$. Simulation results of the proposed ANFIS-PSO and ANFIS-GA controllers of STATCOM after training, were used to compare the damping characteristics on transient stability improvement of the studied system under a three-phase short-circuit fault at the specified buses of the power grid. It was assumed that the three-phase short circuit fault happened on the transmisstion line from the $110 \mathrm{kV}$ Thu Duc Bac substation to $110 \mathrm{kV}$ Intel substaton in $0.1 \mathrm{~s}$. Simulation results are presented in Figures 5 and 6 . These Figures plot the comparative transient responses of the studied system with the proposed STATCOM in the cases of PID controller (black dotted line), with ANFIS-PSO controller (red line) and ANFIS-GA controller (blue line) subject to a threephase short-circuit fault in $0.1 \mathrm{~s}$ from $0.3 \mathrm{~s}$ to $0.4 \mathrm{~s}$. 


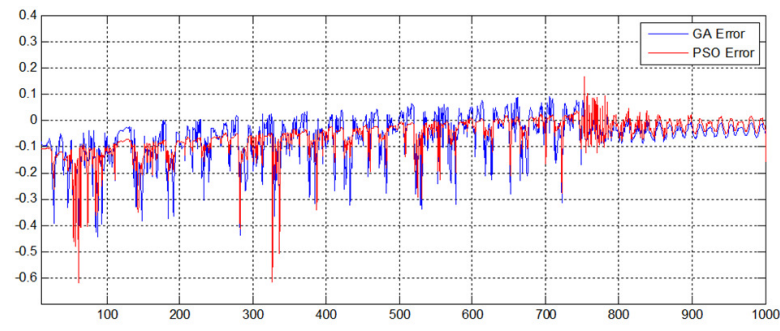

Fig. 4. PSO and GA training results

(a)

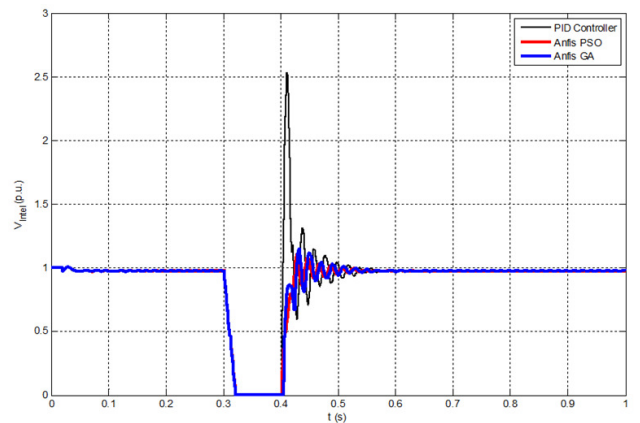

(b)

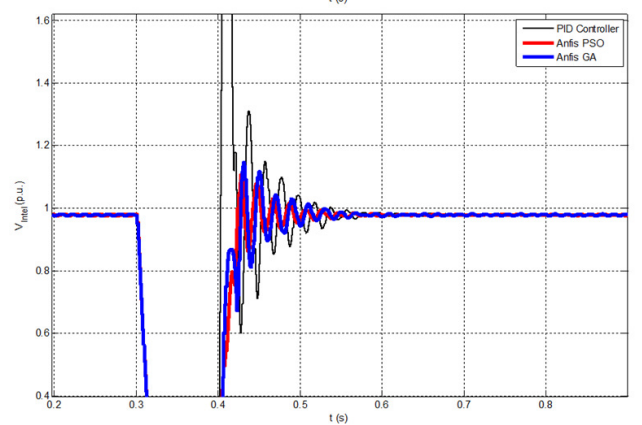

Fig. 5. The voltage of INTEL bus after a three-phase fault. (a) Voltage, (b) zoom in of voltage wave

(a)

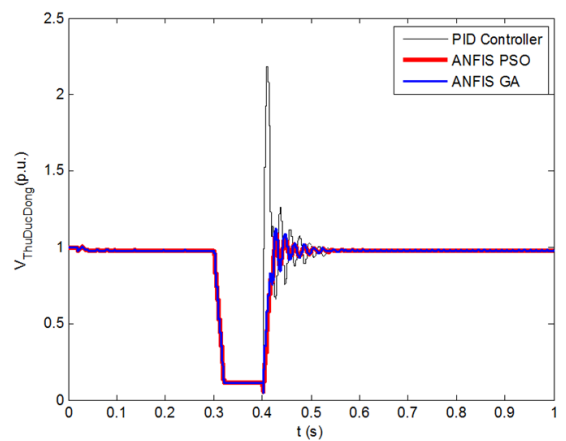

(b)

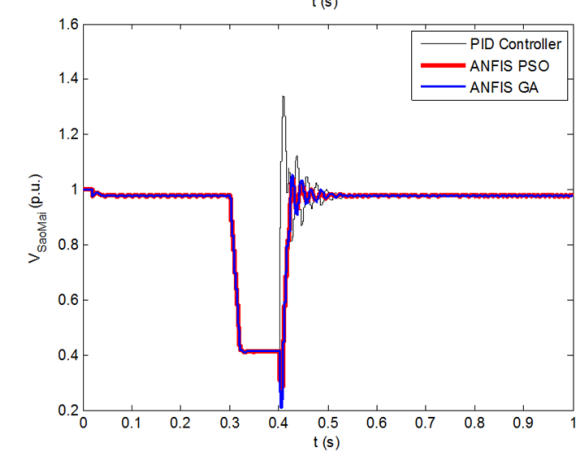

(c)

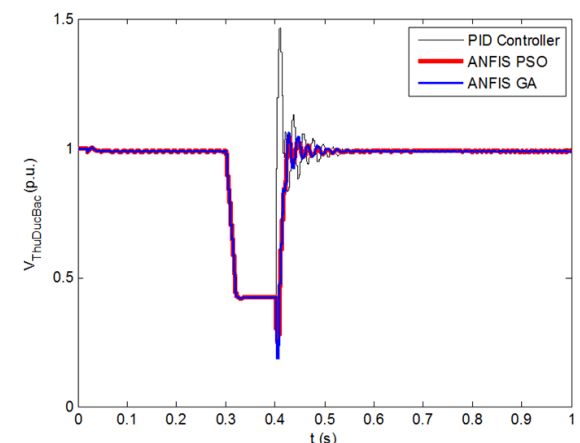

(d)

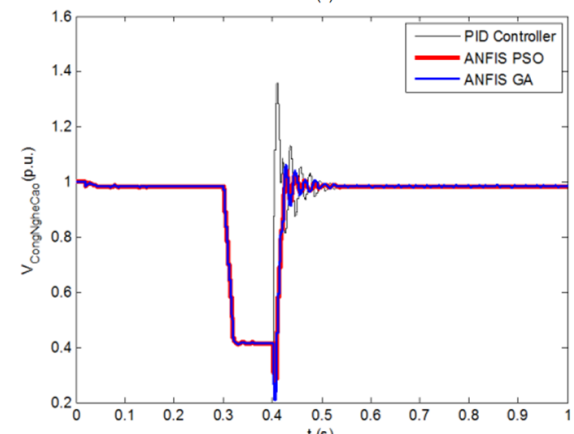

(e)

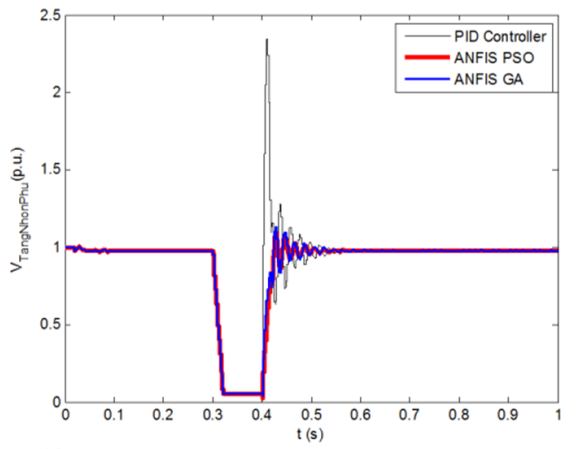

(f)

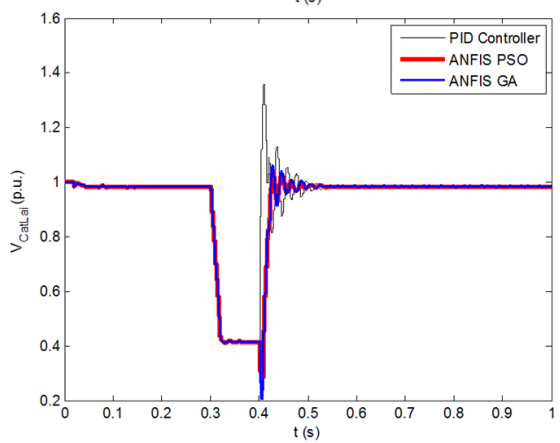

Fig. 6. Response at each bus of the system when a three-phase short circuit fault happened in the Intel bus: (a) Thu Duc Dong bus, (b) Sao Mai bus, (c) Thu Duc Bac bus, (d) Cong Nghe Cao bus, (e) Tang Nhon Phu bus, and (f) Cat Lai bus.

Figure 5 shows the voltage wave of Intel bus after a threephase fault, while Figure 6 shows the voltage of the six buses. With these figures, it can be easily seen that by applying the hybrid PSO-ANFIS and ANFFIS-GA controllers for STATCOM, the output values of these parameters are more stable and more effective, the voltage of each node is improved on overshoot and setting time after a three-phase short circuit fault occured. 
TABLE IV. CONTROLLER RESULT COMPARISON

\begin{tabular}{|c|c|c|c|c|}
\hline \multirow{4}{*}{ Items } & Bus & PID & $\begin{array}{c}\text { ANFIS } \\
\text { GA }\end{array}$ & $\begin{array}{c}\text { ANFIS } \\
\text { PSO }\end{array}$ \\
\hline \multirow{4}{*}{$\begin{array}{c}\text { Setting time } \\
\text { (s) }\end{array}$} & Intel & 0.5373 & 0.4904 & 0.487 \\
\cline { 2 - 5 } & Thu Duc Dong & 0.5374 & 0.4876 & 0.4876 \\
\cline { 2 - 5 } & Cong Nghe Cao & 0.4979 & 0.4571 & 0.4465 \\
\cline { 2 - 5 } & Tang Nhon Phu & 0.5475 & 0.5067 & 0.4877 \\
\cline { 2 - 5 } & Thu Duc Bac & 0.4976 & 0.4468 & 0.4462 \\
\cline { 2 - 5 } & Cat Lai & 0.4977 & 0.4569 & 0.428 \\
\hline \multirow{4}{*}{$\begin{array}{c}\text { Maximum } \\
\text { Voltage (pu) }\end{array}$} & Intel & 2.53 & 1.15 & 1.11 \\
\cline { 2 - 5 } & Thu DucDong & 2.18 & 1.12 & 1.09 \\
\cline { 2 - 5 } & Cong Nghe Cao & 1.36 & 1.06 & 1.04 \\
\cline { 2 - 5 } & Tang Nhon Phu & 2.35 & 1.13 & 1.10 \\
\cline { 2 - 5 } & Thu Duc Bac & 1.46 & 1.06 & 1.04 \\
\hline \multirow{4}{*}{$\begin{array}{c}\text { Percent of } \\
\text { overshoot } \\
\text { (POT) }(\%)\end{array}$} & Cat Lai & 1.36 & 1.06 & 1.04 \\
\cline { 2 - 5 } & Thu Duc Dong & $158 \%$ & $17 \%$ & $13 \%$ \\
\cline { 2 - 5 } & Cong Nghe Cao & $38 \%$ & $8 \%$ & $6 \%$ \\
\cline { 2 - 5 } & Tang Nhon Phu & $139 \%$ & $15 \%$ & $12 \%$ \\
\cline { 2 - 5 } & Thu Duc Bac & $49 \%$ & $8 \%$ & $6 \%$ \\
\cline { 2 - 5 } & Cat Lai & $38 \%$ & $8 \%$ & $6 \%$ \\
\hline
\end{tabular}

By observing the voltage response at the Intel bus shown in Figure 5, it can be seen that the voltage dropped to zero during the fault. The voltage response at Thu Duc Dong and and Tang Nhon Phu also dropped to zero due to these buses neighboring with the Intel bus. However, as shown in the response plotted in Figure 6(b), 6(c), 6(e), and 6(f) the voltage magnitude of Sao Mai, Thu Duc Bac, Cong Nghe Cao, and Cat Lai bus only dropped to 0.4p.u. Based on the operation of the STATCOM and its controllers, a large amount of reactive power was supplied in order to improve the voltage response of the buses. In order to compare the efficiency between controllers, percent of overshoot (POT) indice and setting time were used. These indexes are shown in Table IV. In the case of using ANFIS PSO controller, the POT of voltages at Intel, Thu Duc Dong, Cong Nghe Cao substations were $13 \%, 11 \%$, and $6 \%$, respectively. When using the ANFIS GA controller, the POT of voltages at Intel, Thu Duc Dong, Cong Nghe Cao substations were $17 \%, 14 \%$, and $8 \%$, respectively. Meanwhile, the voltage overshoot in the case of PID controller was $158 \%, 123 \%$, and $38 \%$.

Regarding voltage setting times after fault isolation, which is the time of voltage recovery within the permissible range of $5 \%$, the ANFIS-PSO controller gave the smallest values. With the ANFIS-PSO controller, the voltage setting time at Intel, Thu Duc Dong, Cong Nghe Cao substations was 0.4871s, $0.4876 \mathrm{~s}$, and $0.4465 \mathrm{~s}$, respectively. In the case of PID controller, the voltage setting time was $0.5373 \mathrm{~s}, 0.5374 \mathrm{~s}$, and $0.4979 \mathrm{~s}$, respectively. For a clearer exhibition of the effectiveness of the proposed controllers, Figure 7 shows the simulation results of the studied system when a three-phase short circuit fault occurs at the $110 \mathrm{kV}$ Cong Nghe Cao substation. All the simulation results demonstrate that the preoposed ANFIS-PSO and ANFIS-GA controllers are more effective than the conventional PID controller, and ANFISPSO controller exhibited the best response.

\section{CONCLUSIONS}

This paper presented the results of a research on finding the parameters of membership functions of an adaptive system using particle swarm optimization and genetic algorithms. Hybrid ANFIS-PSO and ANFIS-GA controllers for STATCOM were designed and applied in the Thu Duc power network. STATCOM can support fast response to the system to balance reactive power in the grid, in order to help improving dynamic voltage stability. The simulation results showed that the proposed controllers improve system stability and voltage quality more effective than the conventional PID controller. The ANFIS PSO controller carried out the best response after the occurrence of a three-phase short circuit fault.

(a)

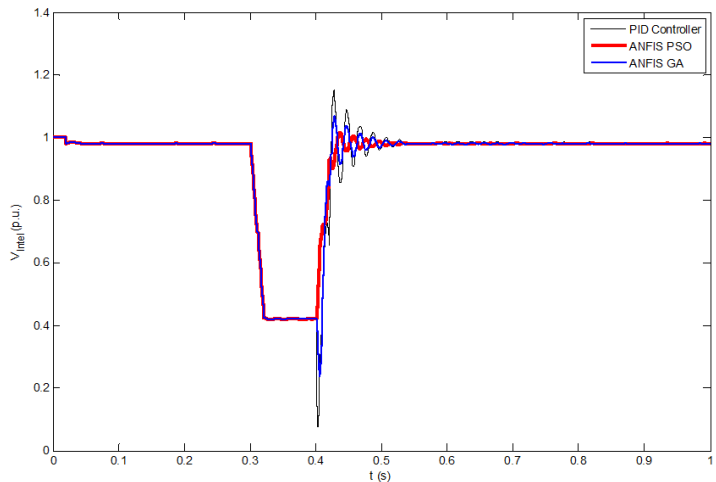

(b)

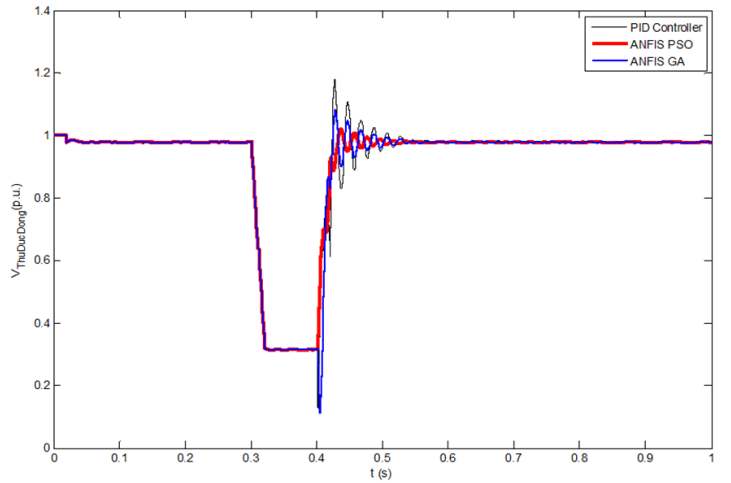

(c)

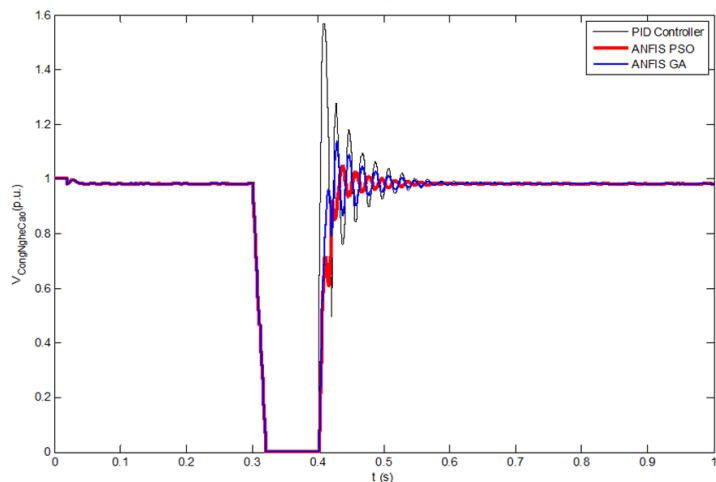

Fig. 7. Responses at each bus of the system when a three-phase short circuit fault happened in the Cong Nghe Cao bus: (a) Intel bus, (b) Thu Duc Dong bus, and (c) Cong Nghe Cao bus.

\section{REFERENCES}

[1] M. Kowsalya, K. K. Ray, D. Kothari, "Voltage stability margin enhancement through the optimal location of var compensator", IEEE 2008 International Conference on Sustainable Energy Technologies, Singapore, November 24-27, 2008 
[2] R. Jadeja, S. Patel, S. Chauhan, "STATCOM: a preface to power quality in power systems performance", Engineering, Technology \& Applied Science Research, Vol. 6, No. 1, pp. 895-905, 2016

[3] M. N. Eskander, S. I. Amer, "Mitigation of voltage dips and swells in grid-connected wind energy conversion systems", 2009 ICCAS-SICE, Fukuoka, Japan, August 18-21, 2009

[4] B. Pokharel, W. Gao, "Mitigation of disturbances in DFIG-based wind farm connected to weak distribution system using STATCOM", North American Power Symposium (NAPS), Arlington, USA, September 2628,2010

[5] Y. M. Alharbi, A. M. S. Yunus; A. A. Siada, "Application of STATCOM to improve the high-voltage-ride-through capability of wind turbine generator", 2011 IEEE PES Innovative Smart Grid Technologies, Perth, Australia, November 13-16, 2011

[6] A. Ganesh, R. Dahiya, G. K. Singh, "Development of simple technique for STATCOM for voltage regulation and power quality improvement", IEEE International Conference on Power Electronics, PEDES, Trivandrum, India, December 14-17, 2016

[7] G. Shahgholian, E. Mardani, A. Fattollahi, "Impact of PSS and STATCOM devices to the dynamic performance of a multi-machine power system", Engineering, Technology \& Applied Science Research, Vol. 7, No. 6, pp. 2113-2117, 2017

[8] H. V. Nguyen, H. Nguyen, K. H. Le, "Hybrid damping controller for STATCOM to enhance power quality in multi-machine system", International Conference on System Science and Engineering, Ho Chi Minh City, Vietnam, July 21-23, 2017

[9] A. Awasthi, S. K. Gupta, M. K. Panda, "Design of a Fuzzy Logic controller based STATCOM for IEEE9 bus system", European Journal of Advances in Engineering and Technology, Vol. 2, No. 4, pp. 62-67, 2015

[10] J. S. R. Jang, "ANFIS: Adaptive-network-based fuzzy inference system”, IEEE Transactions on Systems, Man, and Cybernetics, Vol. 23, No. 3, pp. 665-685, 1993

[11] A. Albakkar, O.P. Malik, "Adaptive neuro-fuzzy FACTS controller for transient stability enhancement", 16th National Power System Conference, December 15-17, Osmania University, India, 2010

[12] H. V. Nguyen, H. Nguyen, K. H. Le, “ANFIS and Fuzzy tuning of PID controller for STATCOM to enhance power quality in multi-machine system under large disturbance", AETA 2018: Recent Advances in Electrical Engineering and Related Sciences: Theory and Application, Ostrava, Czech Republic, September 11-13, 2018

[13] A. Ganesh, R. Dahiya, G. K. Singh, "Development of simple technique for STATCOM for voltage regulation and power quality improvement", IEEE International Conference on Power Electronics, Drives and Energy Systems, Trivandrum, India, Deccember 14-17, 2016

[14] A. Varshney, R. Garg, "Comparison of different topologies of fuzzy logic controller to control D-STATCOM", 3rd International Conference on Computing for Sustainable Global Development, New Delhi, India, March 16-18, 2016

[15] D. Shen, P. W. Lehn, "Modeling, analysis and control of a current source inverter based STATCOM", IEEE Transactions on Power Delivery. Vol. 17, No. 1, pp. 248-253, 2002

[16] J. Jang, C. Sun, E. Mizutani, Neuro-fuzzy and soft computing, Prentice Hall, 1997

[17] J. Kennedy, R. C. Eberhart, "Particle swarm optimization", IEEE International Conference on Neural Networks, Perth, Australia, November 27-December 1, 1995

[18] P.S. You, “An efficient computational approach for railway booking problems", European Journal of Operational Research, Vol. 185, No. 2 , pp. 811-824, 2008

[19] F. Solomonese, C. Barbulescu, S. Kilyeni, M. Litcanu, "Genetic algorithms. Power systems applications", 6th International Conference on Human System Interactions, Sopot, Poland, June 6-8, 2013

\section{AUTHORS PROFILE}

Huu Vinh Nguyen was born in Vietnam. He received his BSc and MSc Degrees from the Electrical and Electronics Engineering Department of Ho
Chi Minh City University of Technology, Vietnam in 2001 and 2009 respectively. He is now working for Ho Chi Minh City Power Corporation, Vietnam. His research fields include power system operation, FACTS, renewable energy, and power quality.

Minh Tien Cao was born in Vietnam. He received his BSc Degree from Telecommunications University, Vietnam in 2008. He received his MSc Degree from Posts and Telecommunications Institute of Technology, Vietnam in 2011. He is now working for the Telecommunications University, Nha Trang City, Vietnam. His research fields include operation and stability of power systems, FACTS, and renewable energy.

Hung Nguyen was born in Vietnam. He received his BSc and MSc Degrees from the Electrical and Electronics Engineering Department of Ho Chi Minh City University of Technology, Vietnam in 2000 and 2004 respectively. He received his $\mathrm{PhD}$ from the Pukyong National University, Korea, in 2010 . He is currently a Associate Professor in the HUTECH Institute of Engineering, Ho Chi Minh City University of Technology (HUTECH), Vietnam. His research interests include nonlinear control, FACTS, power system operation, and renewable energy.

Kim Hung Le was born in Vietnam. He is currently a Professor in the Faculty of Electrical Engineering, University of Science and Technology, University of Danang, Vietnam. His research interests include FACTS, power system protection, and renewable energy. 